\title{
Papers
}

\section{Long term follow up study of survival associated with cleft lip and palate at birth}

\author{
Kaare Christensen, Knud Juel, Anne Maria Herskind, Jeffrey C Murray
}

\begin{abstract}
Objective To assess the overall and cause specific mortality of people from birth to 55 years with cleft lip and palate.

Design Long term follow up study.

Setting Danish register of deaths.

Participants People born with cleft lip and palate between 1943 and 1987, followed to 1998 .

Main outcome measures Observed and expected numbers of deaths, summarised as overall and cause specific standardised mortality ratios.

Results 5331 people with cleft lip and palate were followed for 170421 person years. The expected number of deaths was 259, but 402 occurred, corresponding to a standardised mortality ratio of 1.4 (95\% confidence interval 1.3 to 1.6$)$ for males and 1.8 (1.5 to 2.1) for females. The increased risk of mortality was nearly constant for the three intervals at follow up: first year of life, 1-17 years, and 18-55 years. The participants had an increased risk of all major causes of death.

Conclusions People with cleft lip and palate have increased mortality up to age 55. Children born with cleft lip and palate and possibly other congenital malformations may benefit from specific preventive health measures into and throughout adulthood.
\end{abstract}

\section{Introduction}

The health and survival of people born with congenital malformations such as cleft lip and palate or limb defects are well described in infancy and childhood. ${ }^{1-3}$ A recent study of 117 people with spina bifida provided follow up data to age 35 , but generally the long term prognoses for children with congenital malformations are not known. ${ }^{4}$ Children with repairable anomalies such as cleft lip and palate are often presumed to have normal health and survival in adulthood. Some evidence, however, suggests an increased incidence of cancer early in life among children with some congenital malformations, including cleft lip and palate, and it is unknown whether this susceptibility continues into adulthood. ${ }^{5-7}$ Evidence indicates that parents of children with cleft lip and palate have an increased risk of cancer, which suggests a role for genetic factors. ${ }^{8}$ Population based studies from Scandinavia have found a higher risk of psychiatric diseases and behavioural problems in adults with cleft lip and palate that are associated with increased morbidity. ${ }^{910}$ We used data from Danish registers to assess the long term prognosis associated with cleft lip and palate, particularly overall mortality and cause specific mortality.

\section{Materials and methods}

The Danish cleft lip and palate register is described elsewhere. ${ }^{11-13}$ Ascertainment of Danish people born between 1936 and 1987 with cleft lip and palate has been based on patient lists, and capture-recapture methods indicate ascertainment of $99 \%$ of liveborn affected babies without associated anomalies or syndromes, except submucous cleft palate, which is often asymptomatic. Interestingly, $82 \%$ of the cases were described by chief surgeon Poul Fogh-Andersen. ${ }^{13}{ }^{14}$ We excluded infants with malformations other than cleft lip and palate to eliminate the effect of multiple anomalies on increased mortality. Major malformations were neural tube defects and monogenic traits, syndromes, and sequences, and minor defects were anomalies such as syndactyly of the second and third toes. We did not consider minimal defects, such as small, solitary naevi. Overall, 6627 people were born with cleft lip and palate in Denmark between 1943 and 1987; 6394 (96\%) could be identified through the Danish civil registration system and Danish register of causes of death. We excluded 1063 (17\%) of these people as they had associated anomalies, leaving 5331 people with cleft lip and palate for analysis.

The Danish civil registration system has data on all people residing in Denmark from April 1968 onwards. Individuals are ascribed a unique 10 digit identifier. The register contains information on whether individuals are alive or dead or have emigrated and the date of death or emigration.

The Danish register of causes of death contains information on all deaths and causes of death from 1943 to 1998 in Danish residents. ${ }^{15}$ Cause of death is coded according to revisions of the international classification of diseases: fifth (1943-50), sixth (1951-7), seventh (1958-68), eighth (1969-93), and 10th (1994-8).

We calculated the expected number of deaths by multiplying the observed person years with mortality stratified by sex, one year age groups, and five year calendar period.

\section{Results}

We followed 5331 people with cleft lip and palate for a total of 170421 person years. The expected number of deaths was 259, but 402 occurred: standardised mortality ratio 1.4 (95\% confidence interval 1.3 to 1.6) for males and 1.8 (1.5 to 2.1) for females. The increased risk was almost constant for the three intervals of follow up: first year of life, $1-17$ years, and $18-55$ years (table 1).

Deaths from cancer (36 $v 28$ expected) and cardiovascular events (15 v 13 expected) were only marginally increased in people with cleft lip and palate. The risk of suicide, however, was significantly increased and of similar magnitude in both sexes 
Table 1 Overall mortality from 1943 to 1998 for 5331 Danish people born with cleft lip and palate between 1943 and 1987

\begin{tabular}{|c|c|c|c|c|c|c|c|c|}
\hline \multirow[b]{3}{*}{ Period } & \multicolumn{8}{|c|}{ Age at follow up (years) } \\
\hline & \multicolumn{2}{|c|}{0 to $<1$} & \multicolumn{2}{|l|}{1 to $<18$} & \multicolumn{2}{|c|}{18 to 55} & \multicolumn{2}{|c|}{0 to 55} \\
\hline & $\begin{array}{l}\text { Observed/expected } \\
\text { No of deaths }\end{array}$ & SMR & $\begin{array}{l}\text { Observed/expected } \\
\text { No of deaths }\end{array}$ & SMR & $\begin{array}{l}\text { Observed/ } \\
\text { expected No of } \\
\text { deaths }\end{array}$ & SMR & $\begin{array}{c}\text { Observed/ } \\
\text { expected No of } \\
\text { deaths }\end{array}$ & SMR (95\% CI) \\
\hline \multicolumn{9}{|l|}{ Males: } \\
\hline 1943-64 & $86 / 53.6$ & 1.60 & $27 / 17.8$ & 1.52 & $105 / 72.4$ & 1.45 & $218 / 143.9$ & 1.51 (1.32 to 1.73$)$ \\
\hline $1965-87$ & $21 / 20.8$ & 1.01 & $10 / 9.2$ & 1.09 & $15 / 9.9$ & 1.51 & $46 / 39.9$ & 1.15 (0.84 to 1.54$)$ \\
\hline Total & $107 / 74.5$ & 1.44 & $37 / 27.0$ & 1.37 & $120 / 82.4$ & 1.46 & $264 / 183.8$ & 1.44 (1.27 to 1.62$)$ \\
\hline \multicolumn{9}{|l|}{ Females: } \\
\hline $1943-64$ & $55 / 25.8$ & 2.13 & $14 / 7.92$ & 1.77 & $42 / 26.4$ & 1.59 & $111 / 60.1$ & 1.85 (1.52 to 2.22 ) \\
\hline 1965-87 & $13 / 9.1$ & 1.42 & $7 / 3.9$ & 1.80 & $7 / 2.2$ & 3.14 & $27 / 15.3$ & 1.77 (1.17 to 2.57 ) \\
\hline Total & $68 / 35.0$ & 1.94 & $21 / 11.8$ & 1.78 & $49 / 28.6$ & 1.71 & $138 / 75.4$ & 1.83 (1.54 to 2.16$)$ \\
\hline
\end{tabular}

SMR=standardised mortality ratio.

(standardised mortality ratio 1.6). We found no increased risk for deaths due to accidents, which sometimes comprises "masked" suicides (table 2). Around half of overall deaths were attributed to "other causes." This category comprised mostly "cleft lip and palate" as the cause of death and mainly deaths within the first year of life. As cleft lip and palate is not lethal in itself, we traced 79 of the death certificates for information on the immediate cause of death. In $39 \%$ of cases it was prematurity, whereas pneumonia and bronchopneumonia accounted for $28 \%$ of deaths and postoperative complications for $10 \%$. The remaining cases included asphyxia, aspiration, sepsis, and unknown cause. Other causes of death were mainly attributed to respiratory diseases, infectious diseases, and diseases of the central nervous system. All but diseases of the central nervous system showed moderately increased, but non-significant, standardised mortality ratios (range 1.2-1.6). Mortality due to diseases of the central nervous system, however, showed a significant increased risk for females (9 observed $v 2.6$ expected). Of the nine cases, six were due to epilepsy (1.2 expected, standardised mortality ratio $8.3,1.7$ to 14.2).

We stratified the analysis for type of anomaly (cleft lip only, cleft lip and palate, cleft palate only). The cleft lip only group had only a slight and non-significant increased risk of mortality, whereas it was significant for the cleft lip and palate and cleft palate only groups (table 3).

\section{Discussion}

Children born with cleft lip and palate and no other known malformations seem to have an increased risk of mortality not only in the first year of life but throughout childhood and adulthood. One explanation could be that we included people with discrete malformations associated with cleft lip and palate. This is unlikely since more than $80 \%$ of our cases were described by a surgeon, who was a leading expert throughout the period of ascertainment. ${ }^{13} 14$

Adults with cleft lip and palate have an increased incidence of structural brain anomalies, including major differences in the sizes of the cerebrum and cerebellum associated with mild cognitive impairments. ${ }^{16}$ Such malformations, likely to be missed in routine examination, may predispose to seizures, which were observed as an increased cause of death in this study. These anomalies of the midline are more commonly associated with cleft palate than with cleft lip, and this observation is consistent with the higher risk of early mortality in patients with cleft palate than cleft lip only, as seen in this study. We also observed an increased risk of suicide in both sexes. The cause of suicide is complex, but recognition of potential risk factors affords opportunities for treatment and prevention in people born with birth defects.

Table 2 Mortality from 1943 to 1998 for 5331 people born with cleft lip and palate between 1943 and 1987

\begin{tabular}{|c|c|c|c|c|c|c|c|c|}
\hline \multirow[b]{3}{*}{ Causes of death } & \multicolumn{8}{|c|}{ Age at follow up (years) } \\
\hline & \multicolumn{2}{|c|}{0 to $<1$} & \multicolumn{2}{|c|}{1 to $<18$} & \multicolumn{2}{|c|}{18 to 55} & \multicolumn{2}{|c|}{0 to 55} \\
\hline & $\begin{array}{l}\text { Observed/ } \\
\text { expected No } \\
\text { of deaths }\end{array}$ & SMR & $\begin{array}{c}\text { Observed/ } \\
\text { expected No of } \\
\text { deaths }\end{array}$ & SMR & $\begin{array}{l}\text { Observed/ } \\
\text { expected No of } \\
\text { deaths }\end{array}$ & SMR & $\begin{array}{l}\text { Observed/ } \\
\text { expected No of } \\
\text { deaths }\end{array}$ & SMR (95\% Cl) \\
\hline \multicolumn{9}{|l|}{ Males } \\
\hline $\begin{array}{l}\text { Cancer, cardiovascular } \\
\text { disease, suicide }\end{array}$ & $2 / 0.46$ & 4.36 & $9 / 5.2$ & 1.75 & $47 / 35.1$ & 1.34 & $58 / 40.7$ & 1.43 (1.09 to 1.84$)$ \\
\hline Accident & $2 / 1.53$ & 1.31 & $7 / 12.0$ & 0.58 & $23 / 26.3$ & 0.87 & $32 / 39.8$ & 0.80 (0.55 to 1.13$)$ \\
\hline Other causes: & $98 / 72.5$ & 1.35 & $18 / 10.2$ & 1.76 & $39 / 20.6$ & 1.89 & $155 / 103.3$ & 1.50 (1.27 to 1.76$)$ \\
\hline Cleft lip and palate & 60 & & 4 & & 1 & & 65 & \\
\hline Missing data* & 5 & & 3 & & 11 & & 19 & \\
\hline Total & $107 / 74.5$ & 1.44 & $37 / 27.0$ & 1.37 & $120 / 82.4$ & 1.46 & $264 / 183.8$ & 1.44 (1.27 to 1.62 ) \\
\hline \multicolumn{9}{|l|}{ Females } \\
\hline $\begin{array}{l}\text { Cancer, cardiovascular } \\
\text { disease, suicide }\end{array}$ & $0 / 0.3$ & 0.00 & $2 / 2.2$ & 0.90 & $21 / 16.8$ & 1.25 & $23 / 19.3$ & 1.19 (0.79 to 2.32$)$ \\
\hline Accident & $0 / 0.8$ & 0.00 & $1 / 4.0$ & 0.25 & $9 / 4.8$ & 1.87 & $10 / 9.6$ & 1.05 (0.50 to 1.92$)$ \\
\hline Other causes: & $60 / 33.9$ & 1.77 & $12 / 5.6$ & 2.14 & $13 / 7.0$ & 1.87 & $85 / 46.5$ & 1.83 (1.46 to 2.26$)$ \\
\hline Cleft lip and palate & 34 & & 3 & & 1 & & 38 & \\
\hline Missing data* & 8 & & 6 & & 6 & & 20 & \\
\hline Total & $68 / 35.0$ & 1.94 & $21 / 11.8$ & 1.78 & $49 / 28.6$ & 1.71 & $138 / 75.4$ & 1.83 (1.54 to 2.16 ) \\
\hline
\end{tabular}

SMR=standardised mortality ratio.

${ }^{*}$ Death outside Denmark or no information on death certificate. 
Table 3 Overall mortality from 1943 to 1998 for 5331 people with cleft lip and palate born between 1943 and 1987 stratified for type of cleft lip and palate

\begin{tabular}{|c|c|c|c|c|c|c|c|c|}
\hline \multirow[b]{3}{*}{ Diagnosis } & \multicolumn{8}{|c|}{ Age at follow up (years) } \\
\hline & \multicolumn{2}{|c|}{0 to $<1$} & \multicolumn{2}{|c|}{1 to $<18$} & \multicolumn{2}{|l|}{18 to 55} & \multicolumn{2}{|c|}{0 to 55} \\
\hline & $\begin{array}{c}\text { Observed/ } \\
\text { expected No of } \\
\text { deaths }\end{array}$ & SMR & $\begin{array}{l}\text { Observed/ } \\
\text { expected No of } \\
\text { deaths }\end{array}$ & SMR & $\begin{array}{l}\text { Observed/expected } \\
\text { No of deaths }\end{array}$ & SMR & $\begin{array}{c}\text { Observed/ } \\
\text { expected No of } \\
\text { deaths }\end{array}$ & SMR $(95 \%$ Cl) \\
\hline \multicolumn{9}{|l|}{ Males: } \\
\hline Cleft lip & $25 / 26.9$ & 0.93 & $7 / 9.8$ & 0.72 & $39 / 30.2$ & 1.29 & $71 / 66.9$ & $1.06(0.83$ to 1.34$)$ \\
\hline Cleft lip and palate & $60 / 34.8$ & 1.73 & $19 / 12.6$ & 1.51 & $54 / 38.3$ & 1.41 & $133 / 85.7$ & 1.55 (1.30 to 1.84$)$ \\
\hline Cleft palate & $22 / 12.8$ & 1.72 & $11 / 4.7$ & 2.38 & $27 / 13.8$ & 1.95 & $60 / 31.3$ & 1.92 (1.46 to 2.47 ) \\
\hline All & $107 / 74.5$ & 1.44 & $37 / 27.0$ & 1.37 & $120 / 82.4$ & 1.46 & $264 / 183.8$ & 1.44 (1.27 to 1.62$)$ \\
\hline \multicolumn{9}{|l|}{ Female } \\
\hline Cleft lip & $16 / 11.0$ & 1.46 & $6 / 3.8$ & 1.60 & $10 / 9.1$ & 1.10 & $32 / 23.8$ & 1.34 (0.92 to 1.90$)$ \\
\hline Cleft lip and palate & $33 / 10.8$ & 3.05 & $5 / 3.7$ & 1.36 & $14 / 8.5$ & 1.65 & $52 / 23.0$ & 2.26 (1.69 to 2.97$)$ \\
\hline Cleft palate & $19 / 13.2$ & 1.45 & $10 / 4.4$ & 2.27 & $25 / 11.0$ & 2.27 & $54 / 28.6$ & 1.89 (1.42 to 2.47$)$ \\
\hline All & $68 / 35.0$ & 1.94 & $21 / 11.8$ & 1.78 & $49 / 28.6$ & 1.71 & $138 / 75.4$ & 1.83 (1.54 to 2.16$)$ \\
\hline
\end{tabular}

SMR=standardised mortality ratio.

The increased risk associated with all major causes of death suggests that the cause of excess mortality is complex and multifactorial. We did not have information on birth weight and gestational age, and it is possible that such factors could have attenuated the excess mortality for people with cleft lip and palate.

We hypothesised an increased mortality due to cancer on the basis of reports of an increased occurrence of cleft lip and palate in children with leukaemia and an increased risk of cancer in parents of children with cleft lip and palate. ${ }^{8}{ }^{17}$ We found only a marginally increased mortality due to cancer among people with cleft lip and palate compared with the general population. Thus our data do not support these previous observations.

Considerable attention is paid to the health of children born with congenital malformations or other disabilities, but this is concentrated on the first years of life. As more infants are surviving serious birth defects into adult life it will be increasingly important to understand the clinical course of these disorders to provide optimal preventive health care and to anticipate treatable causes of morbidity and mortality.

Contributors: $\mathrm{KC}$ was responsible for the content, conception, and design of the study, data collection and interpretation, drafting of the manuscript, obtaining funding, administrative support, and supervision. He will act as guarantor for the paper. AMH was responsible for part of the content, for conception and design, interpretation of data, critical revision of the manuscript, and technical support. KJ was responsible for part of the content, analysis and interpretation of the data, critical revision of the manuscript, and statistical expertise. JCM was responsible for the clinical perspective of

\section{What is already known on this topic}

Infants with cleft lip and palate have an increased risk of mortality in the first years of life

Cleft lip and palate may be associated with an increased risk of cancer

\section{What this study adds}

Cleft lip and palate is associated with an increased risk of mortality in infancy and up to age 55

The risk of mortality due to cancer is not substantially increased

The increased risk of mortality in people with cleft lip and palate was attributable to all major causes of death the content, for analysis and interpretation of the data, critical revision of the manuscript, and supervision.

Funding: The Center for the Prevention of Congenital Malformations is supported by a grant from the Egmont Foundation. The Danish Cleft Lip and Palate Database has received support from the National Institute of Dental and Craniofacial Research (grant No R01 DE 11948) and the Egmont Foundation.

Competing interests: None declared.

Ethical approval: The Danish Scientific-Ethical Committee (project Nos $90 / 251$ and $95 / 32)$.

1 Stringer MD, Oldham KT, Mouriquand PDE, Howard ER. Pediatric surgery and urology: long term outcomes. London: WB Saunders, 1998.

2 Mackeprang M. Hay S. Cleft lip and palate mortality study. Cleft Palate J 1972;9:51-63.

3 Hujoel PP, Bollen AM, Mueller BA. First-year mortality among infants with facial clefts. Hujoel PP, Bollen AM, Mueller BA. Fir
Cleft Palate Craniofac J 1992;29:451-5.

Cleft Palate Craniofac J 1992;29:451-5.
Hunt GM, Oakeshott P. Outcome in people with open spina bifida at age 35: prospective community based cohort study. BMJ 2003;326:1365-6.

5 Windham GC, Bjerkedal T, Langmark F. A population-based study of cancer incidence in twins and in children with congenital malformations or low birth weight, Norway, 1967-1980. Am J Epidemiol 1985;121:49-56.

6 Mili F, Khoury MJ, Flanders WD, Greenberg RS. Risk of childhood cancer for infants with birth defects. I. A record-linkage study, Atlanta, Georgia, 1968-1988. Am J Epidemiol 1993;137:629-38.

7 Mili F, Lynch CF, Khoury MJ, Flanders WD, Edmonds LD. Risk of childhood cancer for infants with birth defects. II. A record-linkage study, Iowa, 1983-1989. Am J Epidemiol 1993;137:639-44.

8 Zhu JL, Basso O, Hasle H, Winther JF, Olsen JH, Olsen J. Do parents of children with congenital malformations have a higher cancer risk? A nationwide study in Denmark. Br J Cancer 2002;87:524-8.

9 Ramstad T, Ottem E, Shaw WC. Psychosocial adjustment in Norwegian adults who had undergone standardised treatment of complete cleft lip and palate. II. Self-reported problems and concerns with appearance. Scand J Plast Reconstr Surg Hand Surg 1995;29:329-36.

10 Christensen K, Mortensen PB. Facial clefting and psychiatric diseases: a follow-up of the Danish 1936-1987 facial cleft cohort. Cleft Palate Craniofac J 2002;39:392-6.

11 Christensen K, Schmidt MM, Vaeth M, Olsen J. Absence of an environmental effect on the recurrence of facial-cleft defects. $N$ Engl J Med 1995;333:161-4.

12 Christensen K. The 20th century Danish facial cleft population-epidemiological and genetic-epidemiological studies. Cleft Palate Craniofac J 1999;36:96-104.

13 Christensen K, Fogh-Andersen P. Etiologic subgroups in non-syndromic isolated cleftpalate-a genetic-epidemiologic study of 52 Danish birth cohorts. Clin Genetics $1994 ; 46: 329-35$

14 Fogh-Andersen P. Inheritance of harelip and cleft palate. Copenhagen: Arnold Busck, 1942.

15 Juel K, Helweg-Larsen K. The Danish registers of causes of death. Dan Med Bull 1999;46:354-7.

16 Nopoulos P. Structural brain anomalies in adult males with clefts of the lip and/or palate. Genet Med 2002;4:1-9.

17 Zack M, Adami HO, Ericson A. Maternal and perinatal risk factors for childhood leukemia. Cancer Res 1991;51:3696-701.

(Accepted 1 April 2004)

doi $10.1136 /$ bmj.38106.559120.7C

Center for the Prevention of Congenital Malformations, Institute of Public Health, University of Southern Denmark, DK-5000 Odense, Denmark

Kaare Christensen professor

National Institute of Public Health, DK-2100 Copenhagen, Denmark

Knud Juel senior researcher

Odense University Hospital, Department of Pediatrics, DK-5000 Odense, Denmark Anne Maria Herskind paediatrician 
